4th International Scientific Conference SEC-IASR 2019,

Galati, Romania, 7th - 8th June, 2019

\title{
The Role of Football Methods and Means in Optimizing the Physical Education Lesson
}

\author{
Cătălin Vasile SAVU, Iuliana BARNA \\ https://doi.org/10.18662/lumproc/sec-iasr2019/34
}

How to cite: Savu, C.V., \& Barna, I. (2020). The Role of Football Methods and Means in Optimizing the Physical Education Lesson. In S. Marin \& P. Moisescu (vol. eds.), Lumen Proceedings: Vol. 12. 4th International Scientific Conference SEC-LASR 2019 (pp. 316-326). Iasi, Romania: LUMEN Publishing House. https://doi.org/10.18662/lumproc/sec-iasr2019/34 


\title{
The Role of Football Methods and Means in Optimizing the Physical Education Lesson
}

\author{
Cătălin Vasile SAVU*1, Iuliana BARNA²
}

\begin{abstract}
The present paper aims at detecting the means that can lead to an increase in the efficiency of teaching football in school, in all its aspects. Using the most effective methods for teaching football in physical education classes becomes a priority, and innovations in this field are welcomed as, in this practical way, an improvement of the methodology and especially an improvement of the training content can be achieved.

This paper is meant to identify the means that can lead to an optimisation of football teaching in school, under all its aspects. Using the most effective methods in teaching football becomes a priority and innovations in this field are welcome, as an improvement of the methodology may be achieved and particularly an improvement of the educational content.

The purpose of the research has been to test, during a school year, in the physical education classes, the football-specific methods and means. By using these to a high degree during the physical education classes, an optimisation of the educational process may be achieved, thus acquisition of technical and tactical contents of the football game at this age.

The experiment which took place during an entire school year demonstrated by its results that for the grades where football-specific means were predominanly used, carefully selected and applied methodically, in accordance with the students' morphological and functional abilities, progress was achieved on all levels: anthropometric, motor, technical and tactical, qualitativelly as well as quantitatively.
\end{abstract}

Keywords: method; football game; subject; physical exercise.

\footnotetext{
${ }^{1}$ University of Galati, Romania, catalin.savu@,ugal.ro

${ }^{2}$ University of Galati, Romania, iuliana.barna@,ugal.ro 


\section{Introduction}

The football game contributes to the accomplishment of the physical education tasks, to the development and the improvement of the general psychomotricity, [1] being accessible even to the students of the primary classes, therefore, introducing it at this stage is welcomed and motivated by a decrease in the age when most of sports disciplines start being practised systematically and in an organized matter, hence football, too. Due to its characteristics and multiple positive effects, playing football can substitute some of the traditional means and effects of the physical education lesson.

The popularity and attraction of football is undoubtedly determined by the existence of its own features and characteristics, which give it something extra, something specific compared to the other sports disciplines. Many young people are involved in football organized practice (performance is targeted), but it also has a leisure, active rest (sports leisure) characteristic.

In the study "Issues of Theory and Methodology in Sports Games" it is emphasized that any sports game must be played in a multilateral and convergent way, according to scientific criteria. [4] Thus, sports games are studied from several perspectives:

- as collective sports games;

- as an additional sport;

- as a sports show;

- as an applied sport-science discipline;

- as a teaching subject.

\section{Problem Statement}

In this paper, the authors analyzed the football game from the perspective of the educational subject as a means of physical and sports education.

We considered football an important means of physical education because, through its practice, it contributes to the accomplishment of the tasks of physical education:

- improving health;

- multilateral development of motor capacities;

- acquisition of motor skills and useful life skills;

- acquisition of special knowledge and sports knowledge;

- education of moral qualities, will and aesthetic sense. 


\section{Aims of the research}

The purpose of the research was the systematic observation of the evolution regarding the presence, as a percent, in the lessons of physical education during a school year, of the dominant means and methods in the football game.

The research was also carried in order to identify the most effective means and methods specific to the football game which, used in a balanced way in the physical education lessons, can lead to the optimization of the process of training the students of the 9th and 10th grades, helping the acquisition of the technical-tactical content of the football game at this age. [3]

\section{Organization of the Research}

For the research we have selected grades $9^{\text {th }}$ A (CONTROL GROUP) with a number of 30 students out of which 23 boys, and $9^{\text {th }} \mathrm{B}$ (EXPERIMENTAL GROUP) with a number of 30 students out of which 25 boys. From each class we formed a group of 15 students (working groups), all boys between the ages of 15 and 16, choosing them randomly. The tests were performed by the same qualified teacher, under the same conditions for all students.

We made the initial measurements at the beginning of the first semester during September 16-30, 2018, and the final ones at the end of the second semester during June 2-16, 2019, all separately from the class lessons, following the initial program.

In order to verify the working hypotheses, in the control class the planning was carried out on the basis of the traditional teaching provisions and methodology, and in the experimental class methods and means specific to the football game were used to a high extent in the lessons.

\section{Research Methods}

\section{Football-specific Means used in the Experimental Group}

1. kicking the ball (pass and shot on goal) with the side of the foot or with laces from a standstill or moving position.

2. receiving the ball with the side and the laces from a standstill or moving position, driving the ball alternately with the right and left foot.

3. heading the ball from standstill or from jumping.

4. marking and defense. 
5. dispossession of the opponent having the ball, from the front and the side

6. restart the game from the edge (by the field players) and after scoring a goal (by the goalkeeper).

7. games with a small number of players. [2]

\section{Findings}

Interpretation of the data obtained in the verification tests for the level of acquisition of the football game after using specific methods and means

For the battery of tests used to check the level of acquisition of the football game, based on the results obtained at the initial and final tests, the following assessments can be made:

\section{Test no. 1 "Sense and control of the ball"}

According to the no. 1 chart, the value of the arithmetic mean at the initial test for the control group is 30.1 repetitions - "satisfactory" rating; for the experimental group it is 24.3 repetitions - "satisfactory" rating. The value of the arithmetic mean at the final test is 33.3 repetitions - "satisfactory" rating for the control group, and 52.4 repetitions - "good" rating for the experimental group. Although, for the control group the results were improved by 3.2 repetitions the rating did not improve, it was still "satisfactory". For the experimental group, however, the results improved by 28.1 repetitions, which led to a better rating, namely "good", which shows that the specific means of the football game used in the research were among the best.

The rate of progression $(\mathrm{P})$ is much higher in the experimental group $(115.63 \%) 10.73$ times higher than $(10.73 \%)$ as the control group achieved. 


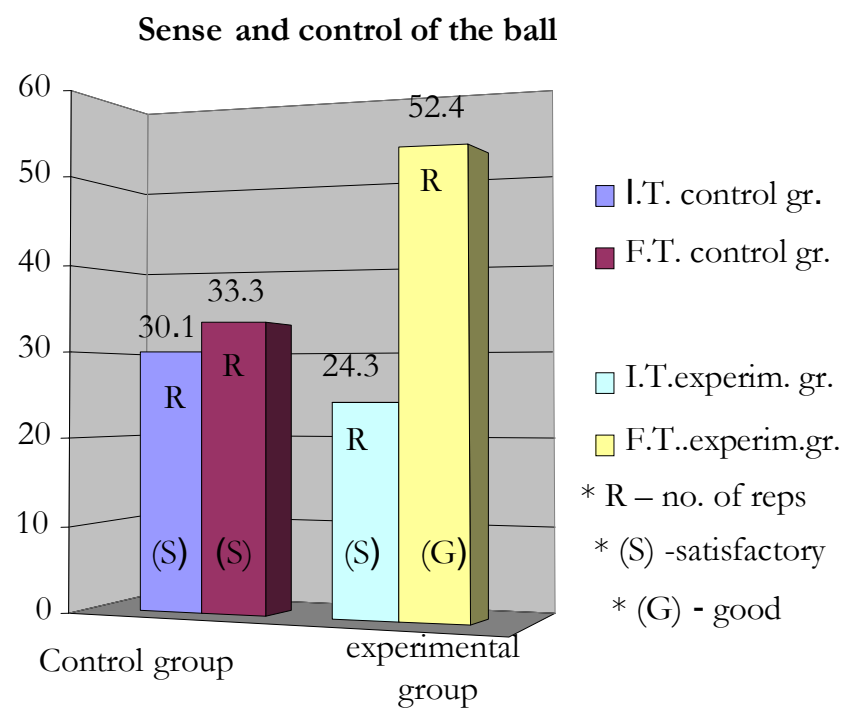

Chart 1 . Test 1 ,,sense and control of the ball”

\section{Test no. 2 "Heading the suspended ball"}

The value of the arithmetic mean at the initial test for the control group is 20.6 repetitions - "satisfactory" rating; for the experimental group it is 20.5 repetitions - "satisfactory" rating. The value of the arithmetic mean at the final test is 22 repetitions - rating "satisfactory" for the control group, and 24.5 repetitions - rating "good" for the experimental group. It can be seen that both groups obtained at the initial testing the "satisfactory" rating, the control group with a very small progress of 1.4 repetitions failed to climb the rating scale while still remaining at the "satisfactory" level, but the experimental group climbed a step on the rating scale to the "good" level with a progress of 4 repetitions. The rate of progression $(\mathrm{P})$ in the experimental group is 2.87 times higher than in the control group. 19.51\%> $6.79 \%$. 


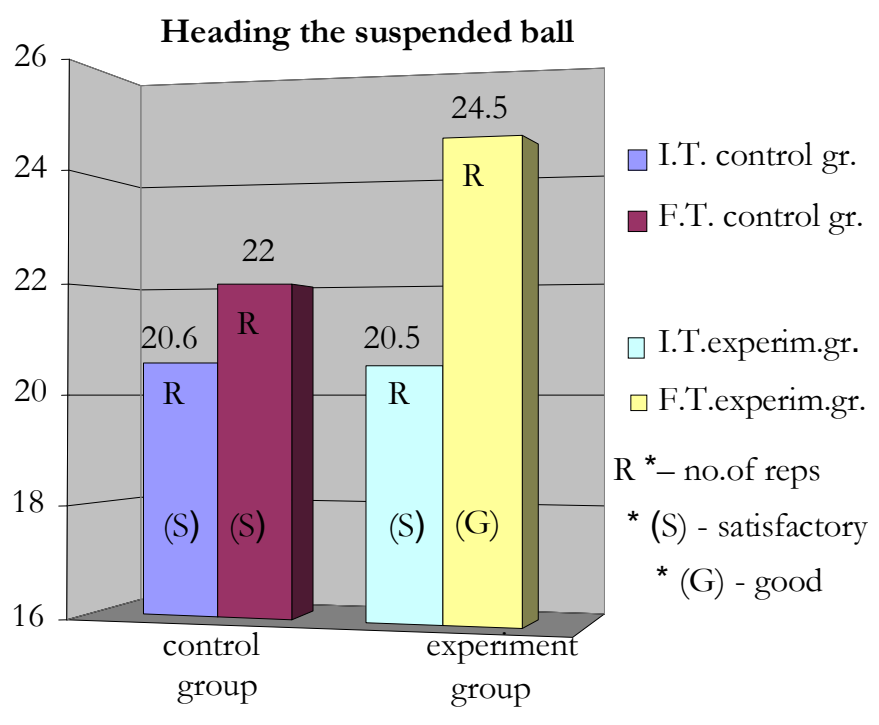

Chart 2. Test 2 "Heading the suspended ball"

\section{Test no. 3 "Shot on two gates"}

According to chart 2, the value of the arithmetic mean at the initial test for the control group is 5.8 goals - "unsatisfactory" rating; for the experimental group it is 5.9 goals - "unsatisfactory" rating. The value of the arithmetic mean at the final test is 6.8 goals - "satisfactory" rating for the control group, and 9.7 goals - "satisfactory" rating for the experimental group. Both groups obtained better results in the final test with a difference of 1 goal for the control group and 3.8 goals for the experimental group, the rating for the two groups was improved and became "satisfactory", but the experimental group had a greater progress than the control group with $\mathbf{2 . 8}$ goals which shows that the specific means of the football game used in the research were useful.

The rate of progression (P) was $64.4 \%$ in the experimental group, 3.73 times higher than that of the control group, which was $17.24 \%$. 


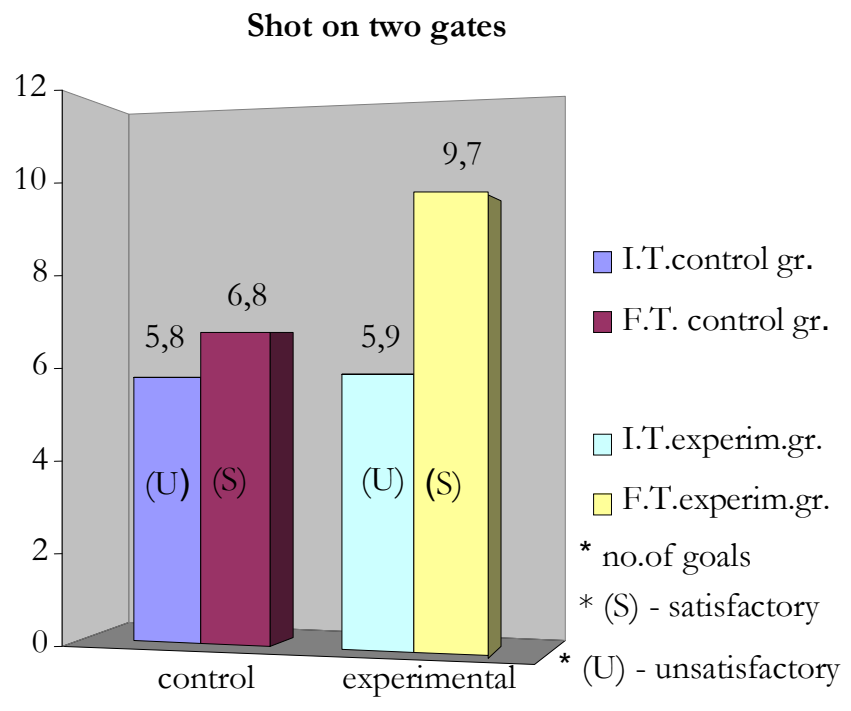

Chart 3. Test 3 ,shot on two gates”

Test no. 4 "Two-handed overhead throw(for field players), one-handed throw for the goalkeeper"

The value of the arithmetic mean at the initial testing for the control group is $16.2 \mathrm{~m}$ - "satisfactory" rating; for the experimental group it is 17.1 $\mathrm{m}$ - "satisfactory" rating. The value of the arithmetic mean at the final test is $18.4 \mathrm{~m}$ - "satisfactory" rating for the control group, and $21.7 \mathrm{~m}$ - "good" rating for the experimental group. Although the results for the control group were improved by $2.2 \mathrm{~m}$, the rating did not improve, it was still "satisfactory". For the experimental group, however, the results improved by $4.6 \mathrm{~m}$, which led to a better rating, namely "good", showing that the specific means of football used in research were among the best. The progress of the experimental group $(26.9 \%)$ is 1.98 times higher than that of the control group $(13.58 \%)$. 


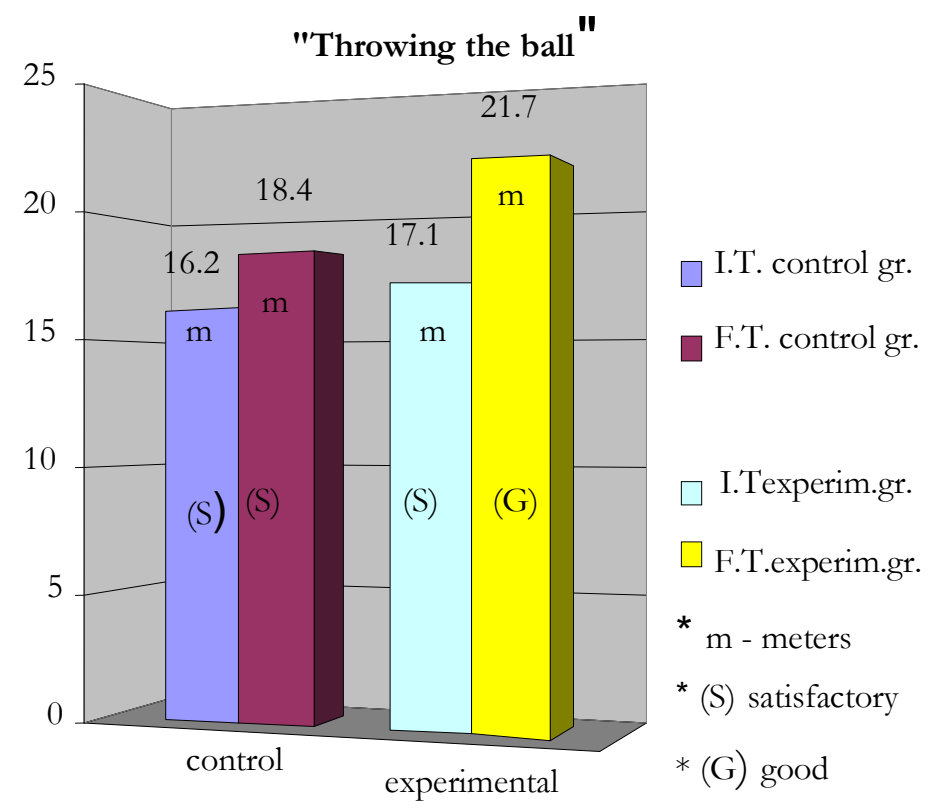

Chart 4. Test 4

"Two-handed overhead throw (for field players) and one-handed throw (for

\section{Test no. 5 "Shot in the bars"} the goalkeeper)"

The value of the arithmetic mean at the initial test for the control group is 13.9 points - "satisfactory" rating; for the experimental group it is 14 points - "satisfactory" rating. The value of the arithmetic mean at the final test is 15.8 points - "satisfactory" rating for the control group, and 21.8 points - "good" rating for the experimental group. Although for the control group the results were improved by 1.9 points, the rating did not improve, it was still "satisfactory". For the experimental group, however, the results improved by $\mathbf{7 . 8}$ points which led to a better rating, that is "good", which showed that the specific means of football used in research were among the best. The rate of progress $(\mathrm{P})$ is 4.07 times higher in favor of the experimental group $55.71 \%>13.66 \%$. 


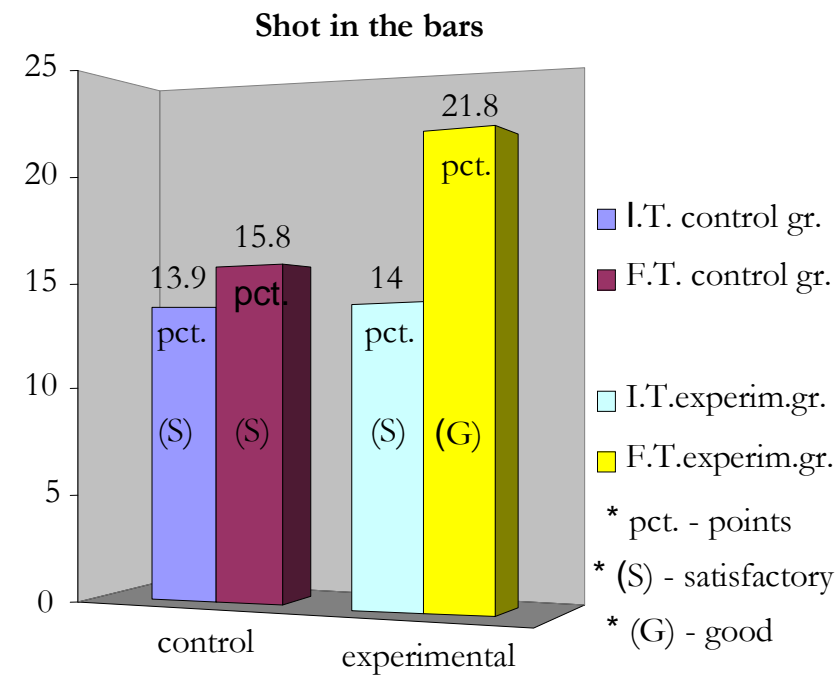

Chart 5. Test 5 "Shot in the bars"

Test no. 6 "The complex test" - includes the basic technical and tactical procedures of the football game (receiving the ball by foot, driving dribbling - among cones, passing, heading the ball or kicking it) plus speed and jumping (when heading the ball).

The value of the arithmetic mean at the initial testing for the control group is 13.6 "- rating" unsatisfactory "; for the experimental group it is 13.5 "-" unsatisfactory "rating. The value of the arithmetic mean at the final test is 13.4 "- rating" unsatisfactory "for the control group, and 12.2" - rating "good" for the experimental group. It can be observed that both groups obtained a very poor result at the initial testing ("unsatisfactory" rating), the control group with a very small progress of -0.2 "failed to climb the rating scale while still remaining at the" unsatisfactory "rating level, the experimental group, however, climbed two steps on the rating scale to the "good" rating with a progression of $\mathbf{- 1 . 3}$ ".

We noticed a significant difference between the two groups in terms of the rate of progression (P): $9.62 \%$ for the experimental group and $1.47 \%$ for the control group (6.55 times smaller). 


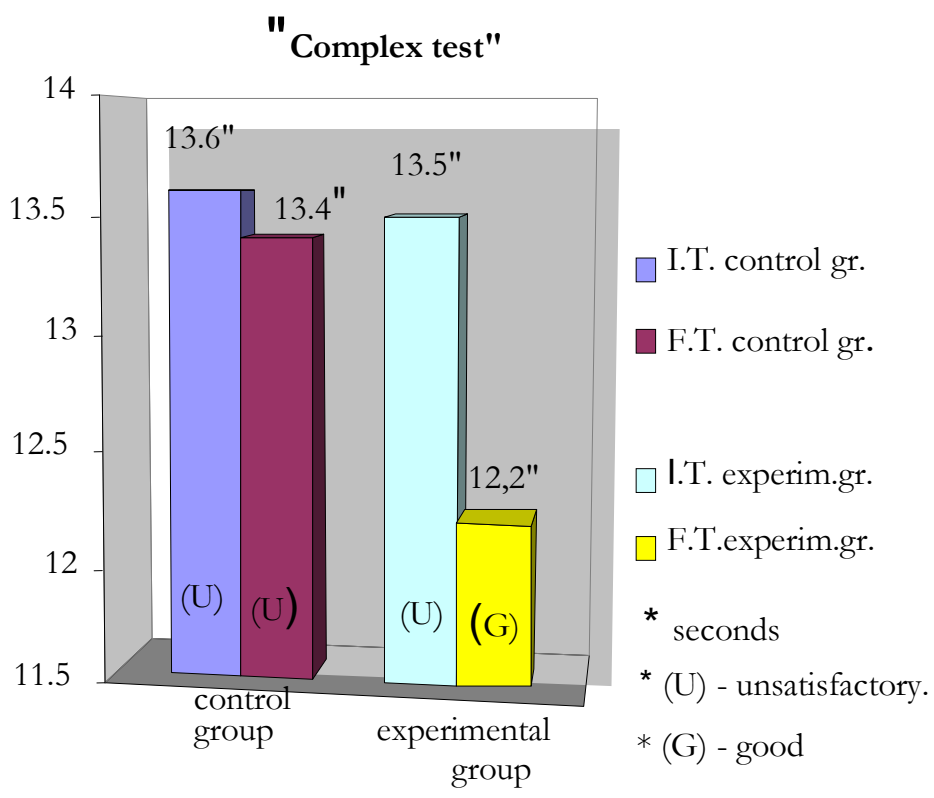

Chart 6. Test 6 "The complex test"

\section{Analysis of the research data}

As to the learning and practice of the football game, the results obtained by the students of the experimental class at the control tests specific to the football game are by far superior to those obtained by the students of the control class. Moreover, by using means belonging to the football game in the physical education lessons to a greater extent, a more psycho-sensory influence was brought among the students by improving the relations between them (collaborations, friendships) relations born and consolidated mainly through the bilateral game, during the actual execution of the tasks of the game. The learning and consolidation contents are achieved much more efficiently through structures of exercises (various but accessible), relay races (especially in the form of a competition), practical sports routes (with specific elements of the football game), and for the improvement issues bilateral play is the most effective means of solving them. We believe that only in this way the football-oriented physical education lesson can fully manifest its formative and educational values, and the purpose pursued by teachers can be quickly and efficiently fulfilled. 
The very serious treatment of the football game, both by physical education teachers and students, during the physical education classes, essentially contributes to the completion and continuity of the training within sports clubs and associations, leading to the permanent supply of increasingly better prepared elements, with an ever-improving performance capacity, on the steps of professional football.

\section{Conclusions}

Collective sports games are a form of manifestation that is based on the playful side of physical exercise, having a special educational value. Their formative feature, so appreciated, is due to the fact that the practice of collective sports games cumulates the positive sanotrophic influences and effects of the physical exercise with the educational influences and effects of the "game". At the same time, playing sports develops the spirit of collaboration and mutual help. The game of football, and not only, primarily stimulates logical and practical thinking.

This accumulation of multilateral influences and positive effects explains the wide spread and popularity of the football game, both as a recreational activity, practiced by many people regardless of their age, but also assimilated among educators. The sports games train the child and the young man in the spirit of subordinating to the interests of the group, considering the personal achievement as integrated in solving the goals of the team.

\section{References}

[1] Preja CA. Didactica educației fizice şi psihomotorii. Pre-primary school. Publisher Editura G.M.I; 2014. 31 p.

[2] Săvescu I. Proiectarea demersului didactic la educație fizică pentru clasele de liceu (IX - XII). Metodologie. Craiova: Editura „Aius”; 2005.

[3] Scarlat E, Scarlat MB. Educație fizică şi sport. Învăţământ liceal. Bucureşti: Editura Didactica şi Pedagogică R.A.; 2003.

[4] Teodorescu L. Probleme de teorie și metodică în jocurile sportive. Bucharest: Ed. Sport-Turism; 1984. 